\title{
DEBATES
}

\section{Espaços de formação doutoral no exterior para docentes de pós-graduação em Direito no Brasil}

\author{
Spaces of doctoral education in law: Brazilian scholars trained \\ abroad
}

\section{Vinicius Wohnrath}

\section{Resumo}

Este artigo explora os locais e momentos de doutoramento no exterior dos docentes atualmente cadastrados em programas de pós-graduação em Direito autorizados pela CAPES. Revisita o trabalho de Engelmann (2008), examinando sua hipótese da constituição de polos de formação na Espanha e na França. O material, coletado na Plataforma Sucupira e no Sistema GeoCAPES, permite confirmar que os países e as instituiçóes formadoras no estrangeiro vêm se diversificando, em um contexto de expansão da pós-graduação na área, iniciada em meados dos anos 1990, e da política científica e de internacionalização da pesquisa jurídica. Considerando a última década, os resultados destacam o aumento da procura por universidades espanholas e portuguesas, fenômeno possivelmente associado ao estreitamento das redes de colaboração entre associaçóes de Direito brasileiras e ibéricas.

\section{Palavras-chave}

Pós-graduação; Campo Jurídico; Circulação Internacional; Pesquisa Jurídica.

\section{Abstract}

This paper aims to explore the places and the periods of academic education received by the Doctors of Juridical Science (J.S.D.) who got their qualifications abroad and are currently working as professors in Brazilian graduate programs in Law. We revisit Engelmann's research (2008) as we examine his hypothesis on the constitution of the Spanish and the French poles concerning the scholars' educational background. The dataset, collected from the Sucupira Platform and the GeoCAPES System, allowed us to verify an upward trend in the number of countries and institutions receiving Brazilian scholars. This diversification process is based on the increasing number of graduate programs in Law beginning in the 1990s in Brazil along with the policies on science and on the internationalization of juridical research. In the last decade, we have identified a recent preference for Spanish and Portuguese universities. This phenomenon is possibly associated with closer collaboration networks between Brazilian and Iberian scientific associations.

\section{Keywords}

Graduate Studies; Juridical Field; International Circulation; Legal Research. 
54 | Vinicius Wohnrath

\section{Introdução}

Este artigo explora a trajetória acadêmica dos professores atualmente credenciados em programas de pós-graduação em Direito no Brasil (PPG-D), focalizando seus lugares de formação no exterior. Em quais países, instituições e momentos ocorreram seus estudos doutorais? A proposta é revisitar dados da pesquisa "Estudos no exterior e mediação de modelos institucionais" (ENGELMANN, 2008), que relaciona treinamento jurídico e circulação de experts. Limitado às fontes disponíveis à época, Engelmann identificou os países de formação e as universidades de atuação no Brasil de parte do corpo docente em Direito em 2006, interpretando a acomodação desse espaço. Concluiu que "quanto às universidades estrangeiras há grande diversificação, com uma tendência - que necessita ser melhor estudada - de formação de polos na Espanha e na França” (2008, p. 156). Sobre essa demanda específica, oferecemos nossas contribuições, testando essa tendência, aqui tratada como hipótese, nos professores cadastrados em 2017.

Para tanto, também estamos considerando que o Brasil é um polo "predominantemente importador de conhecimento científico" (ENGELMANN, 2012, p. 510; DEZALAY e GARTH, 2002). Sendo assim, a "circulação internacional tornou-se um trunfo decisivo na competição entre elites nacionais e internacionais" (ALMEIDA et al., 2004, p. 9). Isso significa que grupos mais internacionalizados dadas suas características, investimentos e possibilidades de inserção - devem possuir importância específica para constituição dos espaços de poder locais, uma vez que "títulos, diplomas e competências adquiridos no estrangeiro vêm se mostrando recursos cabais nos debates sobre reforma do Estado, nas transformações do campo científico e na atribuição de poderes a instituições supranacionais" (ALMEIDA et al., 2004, p. 9).

Interessados especialmente em estabelecer as instituições de ensino no exterior que formaram os docentes ativos em PPG-D, dividimos nosso trabalho em etapas complementares. Inicialmente, tratamos de identificar os momentos e países onde os juristas realizaram seus estudos doutorais. Servidos por dados da Plataforma Sucupira (Documento de Área/Direito; Avaliação Quadrienal) e do Sistema de Georreferenciamento da CAPES (GeoCAPES), colhemos amostras maiores da população (database: arquivo-26.Direito.xlsx, CAPES, 2017b), ampliando as observaçóes de Engelmann (2008) para a última década e abrindo caminho para outras análises desses perfis. Por outro lado, houve desvantagem na obtenção de informaçôes quanto às subáreas de atuação desses docentes ou sobre possíveis financiamentos - demandas específicas que exigem extração individual na Plataforma 
Lattes. Como segundo passo, tabulamos os dados coletados e aplicamos estatística descritiva. Focalizamos, de modo exploratório, as instituiçóes e espaços, conforme as geraçôes de titulados.

Frisamos que o estudo retrata os docentes cadastrados em dezembro de 2017 e a pesquisa com a qual dialogamos repercute sobre aqueles registrados em 2006. As populações não são compostas, necessariamente, pelos mesmos agentes - ainda que, certamente, haja professores comuns às duas análises. Essas diferenças temporais e de composição permitem inspecionar as constâncias e transformaçôes nos padrões de cooptação docente pela área do Direito conforme as geraçôes, além de ampliar os dados sobre os processos de diversificação no campo jurídico brasileiro. Nosso interesse imediato é averiguar os lugares e momentos de doutoramento no exterior, identificando as trajetórias internacionais que repercutem sobre os docentes de pósgraduação em Direito.

\section{Lugares de doutoramento no exterior}

Instrumentalizando a tese da circulação de conhecimento jurídico em democracias periféricas (DEZALAY e GARTH, 1990; 2002), Engelmann encontrou baixa variedade de países onde ocorrem as formaçóes dos professores de Direito atuantes no Brasil. Utilizando dados extraídos da Plataforma Lattes, interpretou os lugares de formação e destino desses experts. Como afirmado, testamos como hipótese a existência de polos de formação na França e na Espanha (ENGELMANN, 2008, p. 156). Assim, nosso primeiro passo foi identificar onde doutoraram-se os docentes atualmente cadastrados em pós-graduaçóes em Direito. Ou seja, onde obtiveram o diploma mais alto na hierarquia dos títulos escolares. Considerando as características dos dados confrontados - a população ora analisada é maior (410 × 2306 indivíduos), mais específica (aperfeiçoamentos, especializações, mestrados, doutorados e pós-doutorados $\times$ apenas doutores atuantes em PPG-D) e com diferença temporal $(>2006 \times>2017)$ para o grupo inspecionado por Engelmann (2008) - variações eram previstas, mas sem que comprometessem a interpretação geral sobre as dinâmicas do espaço.

A pesquisa de referência estimou sua população em 650 agentes, sendo que $65 \%$ deles (410) mantinham currículos no Lattes, podendo ser efetivamente examinados. Neste grupo, 123 declararam ter estudos no exterior em qualquer nível. Portanto, 70\% teve formaçáo apenas no Brasil, enquanto 30\% também passou, em algum momento, ainda que brevemente, por instituiçôes de outros países 
(ENGELMANN, 2008, p. 145-157). Embora possa ser considerada uma taxa relativamente baixa, acreditamos essa valoraçáo demanda melhores parâmetros. Saber como se comportam os formados em outras áreas do conhecimento ajudaria a mensurar os dados para o Direito. Por outro lado, destaca-se a ausência de tradição de estudos no exterior na área jurídica - ao menos no Brasil republicano, acelerando um processo iniciado na década de 1830 , com a substituição gradual da formação em Coimbra por São Paulo ou Olinda/Recife, e, posteriormente, pelas faculdades livres (CARVALHO, 2012; MARTINS e CARVALHO, 2003; VENÂNCIO FILHO, 2011). Por ora, importa que, na Nova República, num contexto de inflação de títulos de graduação, em parte decorrente do número de cursos jurídicos abertos desde os anos 1960, com a expansão da pós-graduação stricto sensu em Direito e com o remodelamento de perfis profissionais, novas trajetórias foram desenvolvidas, incluindo investimentos em estudos no exterior (ENGELMANN, 2006; FRAGALE FILHO e VERONESE, 2004).

Refinando esse grupo amplo que apresenta algum nível de formação internacional, Engelmann assume que, caso a sua pesquisa selecionasse apenas os doutores, as taxas seriam inferiores aos $30 \%$ encontrados. O que não se pode desprezar, por outro lado, é que essas apostas em formaçóes acadêmicas mais altas coincidiram com um momento de incentivo aos aprimoramentos escolares, como comprovado pelas licenças concedidas por órgãos públicos aos seus servidores e pela expansão da oferta de bolsas para pós-graduação (ENGELMANN, 2008, p. 149154).

Essa possível menor frequência de formação doutoral também diz respeito à seletividade desse nível de formação - menos de 220 mil, dos quase 210 milhões de brasileiros, são doutores (ALMEIDA e ZANLORENSSI, 2017; GALVÃO et al., 2016) - e à especificidade da pesquisa jurídica (FRAGALE FILHO e VERONESE, 2004). Já um estudo publicado pelo Observatório do Ensino do Direito, da Fundação Getúlio Vargas, mostra que menos de 1/4 dos 32.049 professores, atuantes nos 2.391 cursos autorizados em 2013, tinha doutorado. Ou seja, uma das áreas com maior número de cursos, docentes e discentes é servida por professores que encontram legitimaçôes em outros espaços, para além do mundo acadêmico e dos altos diplomas escolares. É importante ressaltar que a concentração de doutores ocorre nas universidades públicas e em algumas instituiçóes privadas, como nas confessionais, sobretudo nas regióes Sudeste e Sul (FGV, 2013; GHIRALDI et al., 2013). São esses os centros capazes de manter programas de pós-graduação stricto sensu e de arregimentar docentes mais titulados, funcionando como quadro formador 
estabilizado ao longo do tempo. No Brasil, excluídas as universidades católicas, são as universidades "públicas que detém a hegemonia na formação doutoral" (FRAGALE FILHO e VERONESE, 2004, p. 57).

Esse fenômeno também pode ser explicado pelo perfil multiprofissional dos agentes prestigiados no campo (presentes em julgamentos midiáticos, cortes superiores, autores de doutrina jurídica citada pela jurisprudência...), usualmente com um pé nas salas de aula e outro em escritórios particulares ou no serviço público. Realizar grandes investimentos em titulação acadêmica, que demandam esforços nem sempre compatíveis com os tempos de outros mercados profissionais (clientes, prazos processuais, audiências...), pode não ser a primeira opção dos juristas, sendo que alguns optam apenas por estadias curtas de estudos no estrangeiro (ENGELMANN, 2012, p. 510-512; QUEIROZ et al. 2017, p. 118-120). Basta perceber o lapso temporal entre a graduação e o doutoramento e a dependência das bolsas de estudo fatores que revelam outras fontes de renda e atividades profissionais. Na pesquisa de Martins e Carvalho, 98,2\% dos professores de Direito examinados fizeram seus doutoramentos pouco ou nada incentivados por bolsas e $79 \%$ buscavam o título para seguir carreira docente, ainda que não exclusivamente. Para esse grupo, a "titulação teria proporcionado uma ampliação das oportunidades de trabalho (principalmente para os professores), uma elevação de rendimentos (para aqueles que trabalham na área empresarial) e uma maior participação em eventos e associações" (MARTINS e CARVALHO, 2003, p. 65-68 e p. 71-73).

Essa questão não é novidade nas análises sobre o campo jurídico, marcado pela importância da prática profissional no serviço público e pela militância nas grandes causas da advocacia, como as que envolvem Direitos Humanos. Essa situação deve impactar na dedicação exclusiva para realizar um doutorado completo no exterior, formaçáa que exige período relativamente longo como estudante, em momento inicial da trajetória no mercado prático (ascensão em bancas particulares de advocacia, preparaçáo para concursos públicos, estágio probatório, etc.) e distante dos centros onde é produzido o Direito no Brasil, gerando certo afastamento de oportunidades profissionais e redes sociais aqui constituídas. Noutros termos: “o custo profissional de uma larga estadia fora do Brasil é particularmente elevado para quem, ao lado de pós-graduações, também se dedica as carreiras práticas" (QUEIROZ et al. 2017, p. 119). Essa pode ser uma justificativa válida para as taxas de juristas que se doutoraram fora do País. 
Favorecidos especialmente pelas ferramentas da Plataforma Sucupira, nosso levantamento abrangeu todos os doutores cadastrados em programas de pósgraduação em Direito, conforme os dados divulgados em 2017. Trabalhamos com uma população de 2306 agentes, obtida na última Avaliação Quadrienal. Tabulados a partir de seus lugares de formação, 2008 deles $(87,1 \%)$ se doutoraram em instituições brasileiras e $298(12,9 \%)$ no exterior. Essa será a nossa amostra $1(\mathrm{n}=298)$.

Para entradas duplicadas, consideramos apenas o PPG-D de atuação catalogado em primeiro lugar no banco de dados, geralmente a principal instituição do docente. Com isso, poupamos repetir informações, pois há agentes colaborando em múltiplos programas de pós-graduação. Já quanto à nacionalidade, $8,72 \%$ da população é estrangeira (86 casos). Mas, quando observados apenas os titulados no exterior, essa porcentagem salta para 19,12\%. Entre 1965 e 2017, o Brasil foi o destino de 57 professores estrangeiros e com formação no exterior ( $1 / 5$ do grupo). Quanto às suas origens, não podemos estabelecer um padrão. Constatamos forte diversificação: europeus, latino-americanos etc.

Observando somente os estudos doutorais no exterior, comparando com a população examinada anteriormente, encontramos uma porcentagem inferior à auferida por Engelmann (2008, p. 149) para estudos em qualquer nível $(12,9 \% \times$ $30 \%$ ). Pesquisas vindouras poderão refinar esse dado da pesquisa com a qual dialogamos. A expectativa é que continuem iluminando as transformaçóes ou constâncias nos espaços de formação em alto nível dos juristas, no bojo da cooperação entre instituiçôes que articulam interesses diversos, dos esforços de internacionalização da pós-graduação brasileira e das mudanças nas políticas de financiamento de estudos no exterior durante os governos Lula, Rousseff e Temer. Em relação aos titulados no País, a proporção de formados no exterior continua baixa. Isso significa que um grupo relativamente pequeno gozou de mais tempo (entre o ingresso e a defesa de tese, a média para conclusão do doutorado é de quatro anos), contato e imersão em tradições jurídicas no estrangeiro.

Tabela 1 - Professores titulados no exterior atuantes no Brasil em 2017 (Amostra 1)

\begin{tabular}{l|r}
\hline País de doutoramento no exterior & Frequência absoluta de egressos \\
\hline Espanha & 79 \\
\hline França & 55 \\
\hline Itália & 42 \\
\hline Alemanha & 38 \\
\hline Portugal & 33 \\
\hline Estados Unidos & 28 \\
\hline
\end{tabular}




\begin{tabular}{l|r}
\hline Reino Unido & 5 \\
\hline Bélgica & 4 \\
\hline Suíça & 3 \\
\hline Argentina & 1 \\
\hline Austrália & 1 \\
\hline Canadá & 1 \\
\hline Colômbia & 1 \\
\hline Cuba & 1 \\
\hline México & 1 \\
\hline Paraguai & 1 \\
\hline Polônia & 1 \\
\hline República Checa & 1 \\
\hline Uruguai & 1 \\
\hline Vaticano & 1 \\
\hline Total & 298 \\
\hline Total em países $>1$ & 287 \\
\hline Representatividade excluindo países com valor $=1$ & $96,3087248 \%$ \\
\hline
\end{tabular}

Fontes: Plataforma Sucupira, Avaliação Quadrienal CAPES (2017a; 2018b).

A visão geral dos lugares de doutoramento apresenta como resultado: a Europa Ocidental - Espanha, França, Itália, Alemanha e Portugal - abriga as universidades mais buscadas, seguida pelos Estados Unidos. Como critério de tratamento dos dados, recortamos um grupo de 287 agentes imbricados aos países de representatividade $>1(96,30 \%$ do total). Essa seleção ressaltou a presença majoritária de universidades no eixo entre Europa e EUA. Instituições da Oceania, África e América, com exceção dos estadunidenses, não superaram mais do que um representado cada, não constando dentre os países predominantes.

Tabela 2 - Frequência absoluta e relativa dos docentes em países com representatividade $>1$

\begin{tabular}{l|r|r}
\hline Países & Freq./Absoluta & Freq./Relativa \\
\hline Espanha & 79 & $28 \%$ \\
\hline França & 55 & $19 \%$ \\
\hline Itália & 42 & $15 \%$ \\
\hline Alemanha & 38 & $13 \%$ \\
\hline Portugal & 33 & $11 \%$ \\
\hline Estados Unidos & 28 & $10 \%$ \\
\hline Reino Unido & 5 & $2 \%$ \\
\hline Bélgica & 4 & $1 \%$ \\
\hline
\end{tabular}




\begin{tabular}{l|r|r}
\hline Suíça & 3 & $1 \%$ \\
\hline Total & 287 & $100 \%$ \\
\hline
\end{tabular}

Fontes: Plataforma Sucupira, Avaliação Quadrienal CAPES (2017a; 2017b).

Os dados mostram que a circulação, quanto aos altos níveis de formação, ocorre menos nos países vizinhos ou emergentes, como é o caso do próprio Brasil na ordem mundial. Há indícios de que as tradições jurídicas dos Estados e suas posições na geopolítica acadêmica repercutem sobre o trânsito dos juristas. Em outras áreas, como nas ciências exatas, esse fenômeno talvez se revele de maneira distinta, com pesquisadores presentes em redes acadêmicas inesperadas.

Somos levados a refletir sobre como a produção doutrinária brasileira ainda está concentrada no diálogo com referenciais teóricos - e seus espaços de produção, obviamente - historicamente dominantes em nossa tradição de estudos jurídicos. Destacamos Portugal: além de seus centros de ensino formarem nossos primeiros juristas, muito por conta do monopólio imposto pela Coroa Portuguesa (diferentemente da política da Coroa Espanhola), incorporamos modos de se pensar o Direito e o Estado desde Coimbra (CARVALHO, 1998 e 2012). Nem mesmo a abertura dos primeiros cursos de ciências jurídicas do País resultou na ruptura com esse modelo. Boa parte dos lentes era educada na antiga metrópole e entusiasta de seus métodos de ensino e pensamentos. O fluxo de estudantes através do Atlântico também nunca se extinguiu, embora tenha diminuído com a criação das escolas de São Paulo e Olinda/Recife. Essa gênese se reflete no ensino jurídico estabelecido e de jurista esperado (LOPES, 2000, p. 211; MARTINS e CARVALHO, 2003, p. 5556). Daí que importa, para refletir sobre as dinâmicas do campo, compreendermos as instituiçôes procuradas no exterior conforme as geraçôes de titulados.

\section{Gerações e instituições formadoras no exterior}

Utilizando estatística descritiva, identificamos as instituiçóes e estabelecemos gerações de titulados e pesos ponderados para cada centro formador no exterior. Isso porque, nem todos os países contam com a mesma quantidade de egressos e proporção de universidades. Essas informações permitem observar mais precisamente as escolas formadoras e os seus lugares. Para atribuir a cada instituição um peso relativo ao país onde se encontra, adotamos como critério: a frequência absoluta de egressos para cada instituição $\left(\mathrm{x}_{\mathrm{i}}\right)$ com o peso relativo do país ao qual essa instituição pertence $\left(\mathrm{w}_{\mathrm{p}}\right)$. Considerando que $(\mathrm{w})$ representa o total de docentes da amostra e $\left(\mathrm{w}_{\mathrm{i}}\right)$ o valor absoluto de egressos para cada país, obtivemos assim o peso relativo: 


$$
W p=\frac{w i}{w}
$$

A seguir, calculamos o valor ponderado da instituição acadêmica $\left(\mathrm{x}_{\mathrm{w}}\right)$, visando atingir melhor representatividade dessas instituições segundo os países de formação doutoral dos agentes examinados. Sendo $\left(\mathrm{x}_{\mathrm{i}}\right)$ o valor absoluto de egressos em cada instituição, obtivemos:

$$
\mathrm{Xw}=\frac{x i}{w i} * W p
$$

Estamos assumindo que a circulação de saberes e práticas, nas últimas décadas, vem provocando transformaçóes nos modelos de Estados periféricos, como nos países latino-americanos em reconfiguração jurídica, política, social e econômica pós-ditadura. Nesses processos, orquestrados em nível internacional por diferentes elites, sobressaem-se modelos de pensamento de países centrais, como os Estados Unidos (DEZALAY e GARTH, 1990; 2002). Todavia, pautados pelas informaçóes dispostas no tópico anterior, também supomos que, no Brasil, vem sendo mantida uma carga simbólica específica, relacionada aos estudos jurídicos na Península Ibérica. Essa situação poderia estar associada com as formações das elites historicamente estabelecidas no País, que moldaram o Estado e o sistema jurídico. Percebemos o peso conferido aos países de tradição romano-germânica, justamente a incorporada no Brasil. Universidades imersas em culturas jurídicas diferentes, como a common law, teriam menor procura. Ou, quando buscadas, responderiam a momentos específicos - como o interesse pelos Estados Unidos.

Como essa tarefa também foi enfrentada por Engelmann (2008), possuímos elementos que permitem recuperar interpretaçóes e avançar nos entendimentos sobre possíveis mudanças ou manutençôes nos padrões de estudos no exterior, confrontando o estado anterior com os novos dados obtidos. Para as geraçóes, mantemos a divisão proposta pelo autor de referência. Organizou seus grupos de controle em séries temporais: 1950-1980; 1981-1995; e 1996-2006.

No primeiro conjunto, encontrou 21 casos de estudos no exterior realizados por juristas, com procura pelos EUA ( 9 casos), França (6 casos), Alemanha e Itália (3 casos cada), Espanha, Japão e Suíça (1 cada). Já entre 1981 e 1995, estabeleceu 38 casos, com predomínio da francês (11 casos), italiano (9 casos), alemão (4 casos), 
inglês e estadunidense ( 3 casos cada). Nesse momento, a maior parte dos estudantes cursou doutorado com financiamento. Por fim, entre 1996 e 2006, encontrou "o maior número de docentes com passagem pelo exterior”. Foram 62 casos, indicando "que a maioria dos que atuaram na pós-graduação até 2006 realizaram estudos fora do País nos últimos anos". Nesse período, embora apareçam países latino-americanos, como Argentina e Paraguai ( 2 casos cada), "o predomínio é europeu (Itália, 13 casos; Alemanha, 10 casos; Portugal e Espanha, 9 casos cada; França, 8 casos)" e dos Estados Unidos (8 casos) (ENGELMANN, 2008, p. 152-154).

Quanto à questáo geracional, revisitamos as tendências encontradas por Engelmann (2008) para os agentes formados entre 1950 e 2007, tomando como base a população atualmente ativa. Avançamos com dados até 2017, trabalhando na Amostra 1:

Tabela 3 - Docentes formados no exterior por série temporal

\begin{tabular}{l|l|l|r}
\hline $\begin{array}{l}\text { Série } \\
\text { Temporal }\end{array}$ & $\begin{array}{l}\text { \#Registros - base: Amostra 1 } \\
\text { (Somente doutorados) }\end{array}$ & $\begin{array}{l}\text { \#Registros - base: Engelmann } \\
(2008) \text { (Diferentes modalidades } \\
\text { de estudo/pesquisa) }\end{array}$ & $\begin{array}{c}\text { Variação } \\
\text { \#Registros }\end{array}$ \\
\hline $\begin{array}{l}\mathbf{1 9 6 5 / 5 0 -} \\
\mathbf{1 9 8 0}\end{array}$ & 18 & 21 & -3 \\
\hline $\mathbf{1 9 8 1 - 1 9 9 5}$ & 57 & 38 & +19 \\
\hline $\mathbf{1 9 9 6 - 2 0 0 6}$ & 120 & 62 & +58 \\
\hline $\mathbf{2 0 0 7 - 2 0 1 7}$ & 103 & & +177 \\
\hline Total & 298 casos & 121 casos & \\
\hline
\end{tabular}

Fontes: Plataforma Sucupira, Avaliação Quadrienal CAPES (2017a; 2017b).

Salientamos, todavia, que essa comparação de registros não pode ser realizada de maneira direta. Visamos identificar possíveis novos acomodamentos que, futuramente, podem permitir melhores interpretaçôes sobre o campo jurídico, com olhos para os espaços e mecanismos de legitimação acadêmica das elites brasileiras com acesso às redes internacionais de conhecimento jurídico. Ademais, devemos levar em consideração que o corpo docente dos programas de pós-graduação não é estático, seguindo os desenhos do próprio campo. Mesmo a quantidade de programas vem sendo ampliada: em 1981 havia apenas quatro programas com mestrado e doutorado (FRAGALE FILHO e VERONESE, 2004, p. 55-56). Atualmente, são 36 programas cadastrados pelo GeoCAPES, sem contar os que mantêm apenas o nível mestrado. Essas mudanças estão refletidas no volume da população coletada em 2017, em comparação com os números alcançados em 2006. 
Além desse aumento no número de instituiçôes, identificamos diferenças nas características de formação do corpo docente responsável por orientar os futuros mestres e doutores. Eventos como ingressos, (des)cadastramentos, aposentadorias, mortes, exonerações, etc., tornam a população flutuante, sendo possível apenas retratos instantâneos. Nosso parâmetro é dezembro de 2017, como informado. Engelmann (2008) trabalhou com dados anteriores e encontrou outra composição. Tanto é que seu primeiro caso data de 1950. Já em nossos registros data de 1965 ( $\neq 15$ anos). Devemos considerar, assim, que a pesquisa empírica tem a possibilidade de fornecer explicaçóes e desenvolver argumentos sobre determinado fenômeno, mas será um retrato limitado. Comparar o quadro atual aos períodos anteriores permite ampliar reflexóes sobre as estruturas e dinâmicas do campo conforme novos agentes entram, saem ou são reconfigurados, acompanhando seus investimentos e temáticas prioritárias.

Ademais, lembramos que a série 2007-2016 corresponde ao instante de investimentos do Estado em aprimoramento escolar no estrangeiro (programas de bolsas de estudo, acordos internacionais firmados...), principalmente durante os governos Lula, mas, também, de precariedade e restrição orçamentária em gabinetes posteriores. Considerando o cenário observado por Engelmann $(2007 ; 2008 ; 2017)$ diversificação no campo jurídico brasileiro desde meados dos anos 1990, expansão da pós-graduação, profissionalização da docência em Direito, inflação de títulos acadêmicos e novas formas de ativismo político-judicial com impacto transnacional, como no "combate à corrupção" - teria havido mudança no perfil dos lugares de estudos no exterior? Nessas análises, retomamos a Tabela 3.

\section{Série temporal 1965-1980}

$\mathrm{Na}$ primeira série temporal, a Europa é a região que formou a maior parte dos agentes analisados. Destacam-se França, Itália e Alemanha, seguidas pelos Estados Unidos. Assim, percebemos mudanças para os dados dispostos na pesquisa revisitada, que evidenciaram universidades estadunidenses "a despeito das diferenças históricas de sistemas jurídicos", possivelmente por conta do fomento à pesquisa oferecido por aquele País naquele momento, pelos "efeitos da internacionalização da advocacia durante o regime militar", que favoreceram a militância social "por meio da inserção em redes internacionais de promoção dos Direitos Humanos", e pela "ampliação dos negócios internacionais e da prática da arbitragem comercial internacional”, cuja matriz é norte-americana, com forte impacto na década seguinte (ENGELMANN, 
64 | Vinicius Wohnrath

2008, p. 151-152). Essa colaboração também aparece em investigações sobre o desenvolvimento do campo científico brasileiro, como os lugares da Fundação Ford (CANÊDO, 2017).

Ao tratarmos da geração posterior à ativa em 2006, essa importância norteamericana como centro formador já não aparece com tanta força, ainda que os Estados Unidos ainda representem uma vereda importante para os experts em Direito Econômico e Empresarial. Essa explicação tem mais sentido quando observamos o lapso temporal entre o primeiro titulado em cada uma das pesquisas (1950; 1965). Nas dinâmicas atuais, há diluição entre quatro países formadores, com leve vantagem francesa.

Tabela 4 - Países de formação dos docentes: série temporal 1965-1980

\begin{tabular}{l|r}
\hline Países & \#Casos $\left(w_{i}\right)$ \\
\hline França & 4 \\
\hline Itália & 3 \\
\hline Alemanha & 3 \\
\hline Estados Unidos & 3 \\
\hline Bélgica & 1 \\
\hline Espanha & 1 \\
\hline Reino Unido & 1 \\
\hline Suíça & 1 \\
\hline Vaticano & 1 \\
\hline Total & 18 \\
\hline
\end{tabular}

Fontes: Plataforma Sucupira, Avaliação Quadrienal CAPES (2017a; 2017b).

Percentualmente, encontramos o seguinte resultado: França (com 22\% dos doutorados no exterior dessa geração), Itália, Alemanha e EUA (17\% cada). Novamente, houve variação para a coleta de Engelmann (2008), sendo mais destoante o dado dos Estados Unidos. Essa situaçáo pode ser pensada por diferentes ângulos: [i] em nossos resultados, apreendemos apenas doutorados. O estudo anterior também utilizou outras modalidades de circulação internacional, como aperfeiçoamentos, estágios curtos, especializações, mestrados e pós-doutorados, gerando divergência de dados; ou [ii] considerando o fluxo docente entre 2007 e 2017, certamente ocorreram variaçóes no corpo docente titulado antes de 1980, como aposentadorias, descredenciamentos, etc. A pesquisa de referência registrou uma geração anterior à atualmente ativa. 
Outra observação diz respeito à ausência de doutorados por instituiçóes portuguesas, contrariando nossa previsáo inicial. Nesse instante de circulação internacional, em que o próprio sistema de pós-graduação do Brasil estava se consolidando (CURY, 2004; 2007), com demanda por docentes titulados para atuar como quadro formador no País, universidades historicamente presentes no cenário jurídico brasileiro - como Coimbra ou Lisboa - foram preteridas. Esse fato carece de atenção, especialmente quanto ao momento político português e a situação de seu sistema universitário.

Gráfico 1 - Porcentagem de países de formação: série temporal 1965-1980

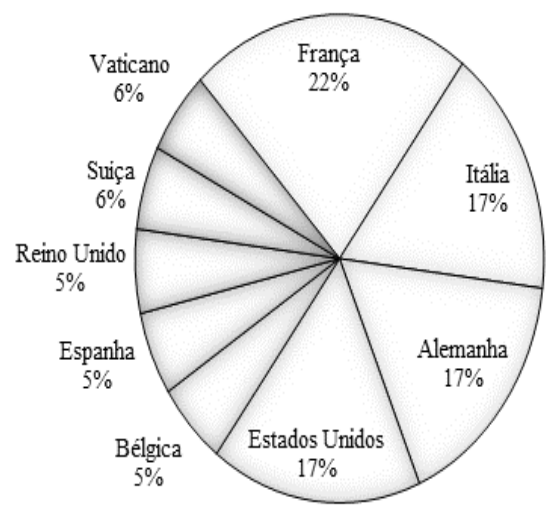

Fontes: Plataforma Sucupira, Avaliação Quadrienal CAPES (2017a; 2017b).

Quanto aos centros formadores, constatamos uma pulverização. Exceto as universidades de Paris I e Frankfurt am Main, com dois titulados cada, todas apresentaram caso único. Ou seja, nessa série temporal não localizamos universidades com capacidade para concentrar uma série permanente de investimentos para estudos doutorais no exterior. Resultado semelhante foi obtido quando examinamos o valor ponderado dos centros formadores por país (na tabela, as setas indicam as maiores taxas). 
Tabela 5 - Instituiçóes formadoras, egressos e valores ponderados: série temporal 1965-1980

\begin{tabular}{|c|c|c|c|}
\hline País/Instituição & Egressos $\left(\mathrm{x}_{\mathrm{i}}\right)$ & $\left(\mathrm{w}_{\mathrm{p}}\right)$ & $\left(\mathrm{x}_{\mathrm{w}}\right)$ \\
\hline Alemanha & 3 & & \\
\hline Christian-Albrechts-Universität Zu Kiel & 1 & 0,333333333 & 0,05555556 \\
\hline Goethe-Universität Frankfurt am Main & $\rightarrow 2$ & 0,6666666667 & 0,11111111 \\
\hline Bélgica & 1 & & \\
\hline Université Catholique de Louvain & 1 & 1 & 0,05555556 \\
\hline Espanha & 1 & & \\
\hline Universidad Pontificia Comillas & 1 & 1 & 0,05555556 \\
\hline Estados Unidos & 3 & & \\
\hline Agnes Scott College & 1 & 0,333333333 & 0,05555556 \\
\hline The Ohio State University & 1 & 0,333333333 & 0,05555556 \\
\hline Tulane University & 1 & 0,333333333 & 0,05555556 \\
\hline França & 4 & & \\
\hline École Pratique des Hautes Études & 1 & 0,25 & 0,05555556 \\
\hline Université de Strasbourg & 1 & 0,25 & 0,05555556 \\
\hline Université Panthéon Sorbonne - Paris I & $\rightarrow 2$ & 0,5 & 0,11111111 \\
\hline Itália & 3 & & \\
\hline Istituto Universitario Europeo & 1 & 0,333333333 & 0,05555556 \\
\hline Pontificio Ateneo Sant'Anselmo & 1 & 0,333333333 & 0,05555556 \\
\hline $\begin{array}{l}\text { Università Degli Studi Di Roma "La Sapie } \\
\text { nza" }\end{array}$ & 1 & 0,333333333 & 0,05555556 \\
\hline Reino Unido & 1 & & \\
\hline Lancaster University & 1 & 1 & 0,05555556 \\
\hline Suíça & 1 & & \\
\hline Université de Genève & 1 & 1 & 0,05555556 \\
\hline Vaticano & 1 & & \\
\hline Pontificia Università Lateranense & 1 & 1 & 0,05555556 \\
\hline Total: 16 instituiçóes & 18 & & \\
\hline
\end{tabular}

Fontes: Plataforma Sucupira, Avaliação Quadrienal CAPES (2017a; 2017b).

\section{Série temporal 1981-1995}

$\mathrm{Na}$ segunda série temporal, além de países europeus, há grande número de egressos dos Estados Unidos - com concentração de titulados em Harvard. Essa informação não passa desapercebida, sabendo-se do contexto da redemocratização dos Estados latino-americanos, com circulação internacional de especialistas em diferentes áreas imbricados com esses processos (DEZALAY e GARTH, 2002). No Brasil, esse momento abrange a reabertura democrática, a Assembleia Constituinte e a formulação de novas interpretações jurídicas e políticas. É o momento de crítica ao Direito Positivo, no cerne de correntes como o Direito Achado na Rua (LYRA 
FILHO, 1987; SOUSA JR., 2015; WOLKMER, 1995) e o Direito Alternativo, já no início dos anos 1990 (ENGELMANN, 2007). Noutra frente, disciplinas sem tanta tradição no campo, como a Sociologia do Direito, foram institucionalizadas em cursos universitários e em grupos de trabalho nos encontros da Associação Nacional de Pós-Graduação e Pesquisa em Ciências Sociais (ANPOCS) e no Conselho Nacional de Pesquisa e Pós-Graduação em Direito (CONPEDI), conforme narra José Eduardo Faria em entrevista ao projeto História Oral do Campo Jurídico em São Paulo (FGV, 2011).

Tabela 6 - Países de formação: série temporal 1981-1995

\begin{tabular}{l|r}
\hline Países & \#Casos $\left(\mathbf{w}_{\mathbf{i}}\right)$ \\
\hline França & 13 \\
\hline Espanha & 11 \\
\hline Itália & 8 \\
\hline Alemanha & 7 \\
\hline Estados Unidos & 7 \\
\hline Portugal & 3 \\
\hline Reino Unido & 2 \\
\hline Austrália & 1 \\
\hline Bélgica & 1 \\
\hline Canadá & 1 \\
\hline México & 1 \\
\hline Polônia & 1 \\
\hline Suí́ça & 1 \\
\hline Total & 57 \\
\hline
\end{tabular}

Fontes: Plataforma Sucupira, Avaliação Quadrienal CAPES (2017a; 2017b).

Nessa série temporal, Portugal aparece no rol de formadores, dominado por instituições francesas, espanholas, italianas e alemãs. Esse é nosso destaque, considerando que nossos resultados destoam dos obtidos por Engelmann (2008): França (11 casos), Alemanha (6 casos), Espanha (4 casos), Inglaterra (3 casos), EUA ( 2 casos) e Japão (1 caso). Os centros de ensino portugueses sequer constavam da coleta na pesquisa de referência, indicando que parte de seus egressos passaram a ingressar em programas de pós-graduação brasileiros após 2007, sempre considerando a população atualmente ativa. Ou seja, em momento de maior estreitamento de relações acadêmicas entre instituições do Brasil e da Península Ibérica (ver série 20072017). Ademais, a variação entre os nossos dados e os examinados anteriormente 
ocorre tanto na ordem dos maiores formadores, quanto dos países menos procurados. Esses lugares periféricos de doutoramento merecerão atenção em estudo vindouro.

Gráfico 2 - Porcentagem de países de formação: série temporal 1981-1995

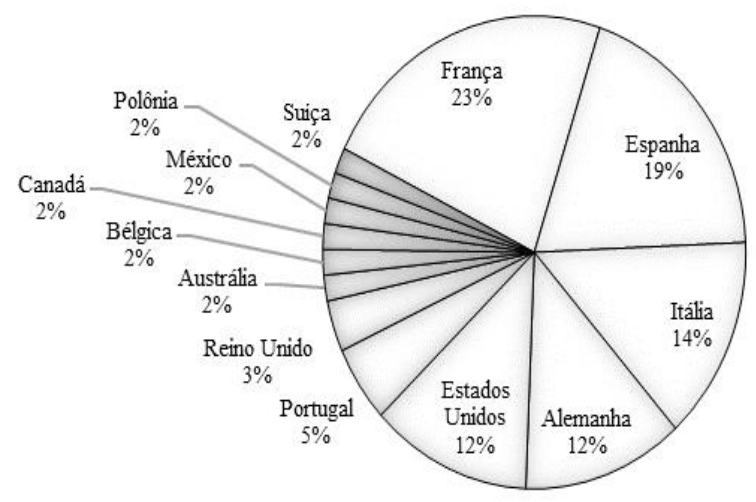

Fontes: Plataforma Sucupira, Avaliação Quadrienal CAPES (2017a; 2017b).

Iluminando os centros formadores, percebemos que Harvard é o local mais procurado para doutoramento. Quanto ao interesse pelos Estados Unidos, recuperamos a interpretação de que, à época, havia amplo "reconhecimento do modelo norte-americano de gestão do Estado e da macroeconomia na América Latina, além de disputas entre elites pelo controle de recursos estatais e do saber legítimo sobre a gestão pública" (ENGELMANN, 2007, p. 489). No contexto das reformas do Estado brasileiro, ao longo dos anos 1990, tratava-se de um capital valorizado, sobretudo por atravessar o Direito, a Administração e a Economia.

Harvard é seguida pela École des Hautes Études en Sciences Sociales (EHESS), instituição criada a partir de uma das seçôes da École Pratique des Hautes Études (EPHE) e especializada em humanidades e ciências sociais. Não mantém programas de formaçáo jurídica em sentido tradicional (como acontece nas universidades de Paris I ou Paris II, que oferecem disciplinas como Direito Processual, Constitucional, Comercial, Tributário, Civil, Penal, etc.), ainda que conte com pesquisadores preocupados com o fenômeno jurídico: como Yves Dezalay, Paolo Napoli ou Liora Israël. Supomos que os docentes formados pela EHESS apresentem trajetórias menos ortodoxas no campo jurídico brasileiro, com forte postura interdisciplinar ou titulação em áreas como a sociologia, a história e a antropologia, 
atuando em universidades marcadas pela crítica ao positivismo jurídico, como algumas da região Sul do Brasil (cf. ENGELMANN, 2006).

Igualmente à série anterior, houve pulverização das instituições formadoras, porém constatamos aumento de universidades tabuladas $(+31,57 \%)$, com abertura para lugares de formação inéditos - incluindo países da América Latina e da Oceania. Todavia, esse movimento foi incapaz de estabelecer polos de atração robustos, em contraposição aos resultados das séries temporais pós-1995. A instituição mais buscada até então, Goethe-Universität Frankfurt am Main, saiu da listagem, e houve diminuição de doutorados pela Université de Paris I.

A italiana Sapienza Università di Roma, que despontava na liderança do levantamento anterior, com seis casos, foi superada por três instituiçóes de ensino, incluindo a espanhola Universidad Complutense de Madrid. Esse fato mostra que uma das previsões do trabalho revisitado foi parcialmente confirmada. Espanha e Itália vêm se mantendo "como polos importantes, tendência que se intensifica no próximo intervalo". Por outro lado, a “diminuição das estadas nos Estados Unidos”, percebida na geração catalogada em 2006, encontra resultado inverso para o grupo ativo em 2017 (ENGELMANN, 2008, p. 153).

Tabela 7 - Instituiçôes formadoras, egressos e valores ponderados: série temporal 1981-1995

\begin{tabular}{l|r|r|r}
\hline País/Instituição & Egressos $\left(\mathrm{x}_{\mathrm{i}}\right)$ & $\left(\mathrm{w}_{\mathrm{p}}\right)$ & $\left(\mathrm{x}_{\mathrm{w}}\right)$ \\
\hline Alemanha & 7 & & 0,142857143 \\
\hline $\begin{array}{l}\text { Albert-Ludwigs- } \\
\text { Universität Freiburg }\end{array}$ & 1 & & 0,01754386 \\
\hline Freie Universität Berlin & 2 & 0,285714286 & 0,035087719 \\
\hline Universität Bremen & 1 & 0,285714286 & 0,035087719 \\
\hline Universität des Saarlandes & 1 & 0,142857143 & 0,01754386 \\
\hline $\begin{array}{l}\text { Westfälische Wilhelms - } \\
\text { Universität Münster }\end{array}$ & 1 & & \\
\hline Austrália & 1 & & 0,01754386 \\
\hline $\begin{array}{l}\text { University of New England, Arm } \\
\text { idale }\end{array}$ & 1 & & \\
\hline Bélgica & 1 & & 0,01754386 \\
\hline Université Libre de Bruxelles & 1 & & \\
\hline Canadá & 1 & & 0,01754386 \\
\hline Université du Québec, Montréal & 11 & & \\
\hline Espanha & 2 & 0,181818182 & 0,035087719 \\
\hline Universidad Autónoma de Madri & & & \\
d & & & 1 \\
\hline
\end{tabular}


Vinicius Wohnrath

\begin{tabular}{|c|c|c|c|}
\hline $\begin{array}{l}\text { Universidad Complutense de Mad } \\
\text { rid }\end{array}$ & $\rightarrow 3$ & 0,272727273 & 0,052631579 \\
\hline Universidad de Sevilla & 2 & 0,181818182 & 0,035087719 \\
\hline Universidad de Valladolid & 1 & 0,090909091 & 0,01754386 \\
\hline $\begin{array}{l}\text { Universidad Nacional de Educaci } \\
\text { on a Distancia }\end{array}$ & 1 & 0,090909091 & 0,01754386 \\
\hline $\begin{array}{l}\text { Universitat Autònoma de Barcelo } \\
\text { na }\end{array}$ & 1 & 0,090909091 & 0,01754386 \\
\hline Universitat de València & 1 & 0,090909091 & 0,01754386 \\
\hline Estados Unidos & 7 & & \\
\hline $\begin{array}{l}\text { California University of Managem } \\
\text { ent and } \\
\text { Sciences }\end{array}$ & 1 & 0,142857143 & 0,01754386 \\
\hline Harvard University & $\rightarrow 4$ & 0,571428571 & 0,070175439 \\
\hline Indiana University & 1 & 0,142857143 & 0,01754386 \\
\hline New York University & 1 & 0,142857143 & 0,01754386 \\
\hline França & 13 & & \\
\hline $\begin{array}{l}\text { École des Hautes Études en Scie } \\
\text { nces Sociales }\end{array}$ & $\rightarrow 3$ & 0,230769231 & 0,052631579 \\
\hline Université de Rennes I & 1 & 0,076923077 & 0,01754386 \\
\hline Université de Strasbourg & 1 & 0,076923077 & 0,01754386 \\
\hline $\begin{array}{l}\text { Université Panthéon Sorbonne - } \\
\text { Paris I }\end{array}$ & 1 & 0,076923077 & 0,01754386 \\
\hline $\begin{array}{l}\text { Université Panthéon-Assas - } \\
\text { Paris II }\end{array}$ & 2 & 0,153846154 & 0,035087719 \\
\hline $\begin{array}{l}\text { Université Paris-Sorbonne - } \\
\text { Paris IV }\end{array}$ & 1 & 0,076923077 & 0,01754386 \\
\hline $\begin{array}{l}\text { Université Sorbonne Nouvelle - } \\
\text { Paris III }\end{array}$ & 1 & 0,076923077 & 0,01754386 \\
\hline Université Toulouse I - Capitole & $\rightarrow 3$ & 0,230769231 & 0,052631579 \\
\hline Itália & 8 & & \\
\hline European University Institute & 1 & 0,125 & 0,01754386 \\
\hline $\begin{array}{l}\text { Università Degli Studi Di Camer } \\
\text { ino }\end{array}$ & 2 & 0,25 & 0,035087719 \\
\hline $\begin{array}{l}\text { Università Degli Studi Di Roma } \\
\text { "La Sapienza" }\end{array}$ & $\rightarrow 3$ & 0,375 & 0,052631579 \\
\hline $\begin{array}{l}\text { Università Degli Studi Di Roma } \\
\text { "Tor Vergata" }\end{array}$ & 1 & 0,125 & 0,01754386 \\
\hline Università Degli Studi Di Siena & 1 & 0,125 & 0,01754386 \\
\hline México & 1 & & \\
\hline $\begin{array}{l}\text { Universidad Nacional Autónoma } \\
\text { de México }\end{array}$ & 1 & 1 & 0,01754386 \\
\hline
\end{tabular}




\begin{tabular}{l|r|r|r}
\hline Polônia & 1 & & \\
\hline $\begin{array}{l}\text { Uniwersytet Mikoaja Kopernika } \\
\text { W Toruniu }\end{array}$ & 1 & 1 & 0,01754386 \\
\hline Portugal & 3 & & \\
\hline Universidade de Coimbra & 2 & 0,666666667 & 0,035087719 \\
\hline Universidade Nova de Lisboa & 1 & 0,333333333 & 0,01754386 \\
\hline Reino Unido & 2 & & 0,01754386 \\
\hline University of London - & 1 & 0,5 & 0,01754386 \\
The London School... & 1 & & \\
\hline $\begin{array}{l}\text { University of London - } \\
\text { University College London }\end{array}$ & 1 & & 0,01754386 \\
\hline Suíça & 1 & & \\
\hline Université de Genève & 57 & & \\
\hline Total: 39 instituiçóes & & & \\
\hline
\end{tabular}

Fontes: Plataforma Sucupira, Avaliação Quadrienal CAPES (2017a; 2017b).

Detalhando as frequências ponderadas, Harvard concentra 57,14\% dos titulados nos Estados Unidos, convertendo-se em centro importante no montante. $\mathrm{Na}$ França, esse cenário é compartilhado entre a EHESS e Université Toulouse I Capitole $(23,07 \%$ cada). Nenhuma delas apareceu no rol anterior, mas, em séries posteriores $(<2017)$, tornaram-se constantes.

\section{Série temporal 1996-2006}

Examinando as trajetórias dos docentes atualmente ativos em programas de pós-graduação brasileiros, desde meados dos anos 1990 a Espanha vem despontando como sendo o país mais procurado para doutoramento. Considerando que Portugal também se destacou, figurando como terceiro local preferido, na série 1996-2006 a Península Ibérica apresenta saltos numéricos - tanto de egressos, quanto de instituições. $\mathrm{Na}$ atualidade, é a região que mais cresce.

Esse avanço das instituiçóes ibéricas já vinha sendo salientado no artigo revisitado, indicando uma transição nos lugares de estudos e nos perfis da população. A geração examinada em 2006 apontava para essa mudança, por ora confirmada supondo, ainda, que alguns professores estão ativos ao longo dos períodos. Há dez anos, esse contexto permitiu que Engelmann (2008) estabelecesse como tendência a organização de polos - o que, de fato, verificamos nessa série temporal e, em parte, na posterior. 
Quando comparados os resultados atuais e anteriores, percebemos que os demais países mantiveram suas posiçóes, com variações na ordem. Ressaltamos que tanto em nosso levantamento (120 casos), quanto na coleta de Engelmann (62 juristas, 27 com doutoramento no estrangeiro), a série 1996-2006 é a que apresenta maior número de titulados no exterior e em lugares em comum (ENGELMANN, 2008, p. 153-155). Sem desprezar outras explicações possíveis, esse fato pode estar relacionado com os momentos da carreira daqueles que obtiveram seus títulos em meados da década de 1990. Hoje na faixa dos 55 anos de idade, estão plenamente ativos, atravessando duas séries temporais. Desta feita, nossas taxas e as disponíveis na pesquisa de referência começam a se aproximar bastante.

Ademais, trata-se do instante da expansão da pós-graduação em Direito, que trouxe a demanda por professores altamente titulados (FRAGALE FILHO e VERONESE, 2004; MARTINS e CARVALHO, 2003). A passagem pelo exterior parece ter sido privilegiada, ao conferir uma legitimação valorizada nas trajetórias acadêmicas desses agentes. Também devemos considerar a inflação de títulos de bacharel em Direito, a diversificação do campo jurídico e a valorização profissional de diplomas acadêmicos, além da abertura internacional brasileira, após as crises econômicas das décadas de 1980 e 1990, e das políticas de fomento à pesquisa implantadas mais recentemente, cujo debate está presente em literatura específica (ENGELMANN, 2004; 2006; 2008; 2017).

Tabela 8 - Países de formação: série temporal 1996-2006

\begin{tabular}{l|r}
\hline Países & \#Casos $\left(\mathbf{w}_{\mathbf{i}}\right)$ \\
\hline Espanha & 43 \\
\hline França & 17 \\
\hline Portugal & 16 \\
\hline Alemanha & 15 \\
\hline Itália & 13 \\
\hline Estados Unidos & 10 \\
\hline Bélgica & 2 \\
\hline Argentina & 1 \\
\hline Cuba & 1 \\
\hline Paraguai & 1 \\
\hline República Checa & 1 \\
\hline Total & 120 \\
\hline Ponts: Plat
\end{tabular}

Fontes: Plataforma Sucupira, Avaliaçấo Quadrienal CAPES (2017a; 2017b). 
A partir dessa amostra, percebemos que os doutores provenientes de universidades espanholas superam em 26 titulados o segundo país mais procurado. $\mathrm{Na}$ listagem, a sequência composta por França, Portugal, Alemanha e Itália é mais equilibrada - com 17, 16, 15 e 13 casos, respectivamente. Buscando por permanências, sublinhamos três espaços que se mantêm dentre os mais buscados desde a primeira geração: Alemanha, França e Itália. Servem como verdadeiros países ancoradouros, praticamente estáveis em todas as séries temporais examinadas. Acreditamos que essas relações também estejam refletidas na doutrina jurídica consumida e produzida no Brasil, com importaçáo de ideias e interpretações de países que vem se mostrando historicamente centrais para formação dos juristas brasileiros ao lado de Espanha e Portugal, em destaque nos últimos anos e nos primeiros momentos da conformação do Estado brasileiro. Suscitando uma relação que merece ser melhor estudada futuramente, esse dado também pode fornecer pistas sobre possíveis ligações entre certos centros de ensino no exterior e a própria formulação do espaço acadêmico nacional para a área do Direito, considerando as possibilidades de inserção internacional de alguns de seus agentes.

Para o grupo ativo em 2017, reforçamos que nos últimos dez anos houve vantagem numérica para egressos de universidades espanholas. Essa era, parcialmente, a previsão em 2006. A pesquisa de referência revelou a diversificação dos locais de estudos, sem identificar distanciamentos entre o número de formados por país: Itália (13 casos), Alemanha (10 casos), Portugal (9 casos), Espanha (9 casos), França (8 casos), Estados Unidos (8 casos) e Canadá (2 casos). Nesse cenário, foi percebido que os "países mais centrais e predominantes nos outros intervalos analisados perderam espaço” para instituiçôes italianas e ibéricas (ENGELMANN, 2008, p. 153-154). Essa situação, de certo modo, persiste nos dados coletados atualmente. 
74 | Vinicius Wohnrath

Gráfico 3 - Porcentagem de países de formação: série temporal 1996-2006

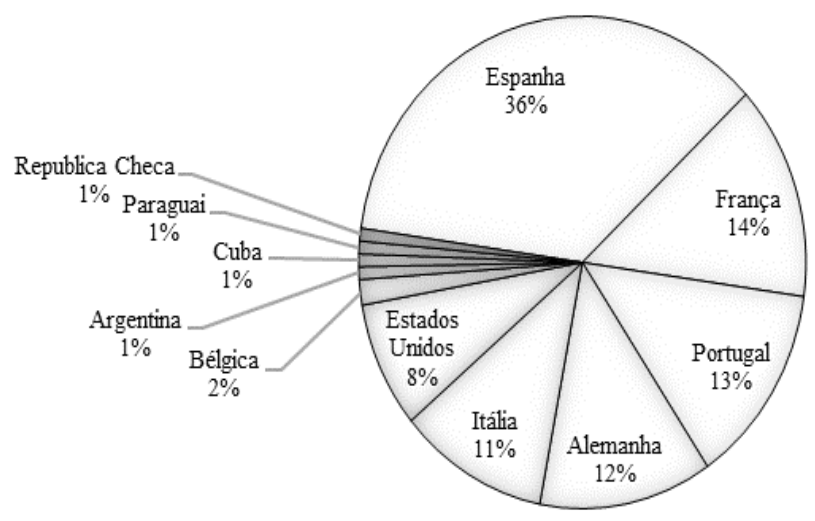

Fontes: Plataforma Sucupira, Avaliação Quadrienal CAPES (2017a; 2017b).

Além do volume de titulados, a Espanha desponta em número de instituições - com 21 universidades catalogadas. Ao ponderarmos os valores relativos, identificamos uma boa distribuição entre elas. No núcleo principal, aparece a já esperada (considerando a frequência anterior) Universidad Complutense de Madrid e a Universitat de Barcelona. Outros centros também surgem na listagem, muitos pela primeira vez, como as universidades de València, Deusto e Sevilla. Praticamente todo o território espanhol atraiu doutorandos que, posteriormente, viriam a atuar no Brasil. Por outro lado, constatamos situação inversa em Portugal, onde houve alta concentraçáo de egressos da Universidade de Coimbra. Esse dado, possivelmente relacionado com a história social dos espaços observados, elevou o peso relativo dessa instituição, ainda que os portugueses não constem dentre os dois países com maior quantidade de egressos.

Conforme Engelmann, o predomínio europeu nessa série, também verificado em suas coletas, está fortemente vinculado à uma formação de matriz publicista. Esse direcionamento indica uma "estreita vinculação do campo acadêmico do Direito com as demandas das práticas judiciais advindas da redemocratização". Portanto, "a redefinição das funções de Estado e a expansão do poder político da magistratura e de outras carreiras jurídicas afinaram-se à legitimação dos produtos acadêmicos e à expansão massiva da pós-graduação em Direito Público” (ENGELMANN, 2012, p. 495). 
Tabela 9- Instituiçôes formadoras, egressos e valor ponderado: série temporal 1996-2006

\begin{tabular}{|c|c|c|c|}
\hline País/Instituição & Egressos $\left(\mathrm{x}_{\mathrm{i}}\right)$ & $\left(\mathrm{w}_{\mathrm{p}}\right)$ & $\left(\mathrm{x}_{\mathrm{w}}\right)$ \\
\hline Alemanha & 15 & & \\
\hline Christian-Albrechts-Universität Zu Kiel & 1 & 0,066666667 & 0,008333333 \\
\hline Goethe-Universität Frankfurt am Main & 1 & 0,0666666667 & 0,008333333 \\
\hline Humboldt-Universität Zu Berlin & 1 & 0,0666666667 & 0,008333333 \\
\hline Johannes Gutenberg-Universität Mainz & 1 & 0,0666666667 & 0,008333333 \\
\hline Ludwig-Maximilians-Universität München & 2 & 0,133333333 & 0,016666667 \\
\hline Ruhr-Universität Bochum & 1 & 0,066666667 & 0,008333333 \\
\hline Ruprecht-Karls-Universität Heidelberg & 1 & 0,066666667 & 0,008333333 \\
\hline Universität Des Saarlandes & 1 & 0,0666666667 & 0,008333333 \\
\hline Universität Kassel & 1 & 0,0666666667 & 0,008333333 \\
\hline Universität Osnabrück & 1 & 0,066666667 & 0,008333333 \\
\hline Universität Regensburg & 1 & 0,066666667 & 0,008333333 \\
\hline Universitätsklinikum Heidelberg & 1 & 0,066666667 & 0,008333333 \\
\hline Westfälische Wilhelms - Universität Münster & 2 & 0,133333333 & 0,016666667 \\
\hline Argentina & 1 & & \\
\hline Pontificia Universidad Católica Argentina & 1 & 1 & 0,008333333 \\
\hline Bélgica & 2 & & \\
\hline Université Catholique de Louvain & 2 & 1 & 0,016666667 \\
\hline Cuba & 1 & & \\
\hline Universidad de Oriente & 1 & 1 & 0,008333333 \\
\hline Espanha & 43 & & \\
\hline Universidad Autónoma de Madrid & 1 & 0,023255814 & 0,008333333 \\
\hline Universidad Carlos III de Madrid, Getafe & 1 & 0,023255814 & 0,008333333 \\
\hline Universidad Complutense de Madrid & $\rightarrow 7$ & 0,162790698 & 0,058333333 \\
\hline Universidad de Alcalá & 1 & 0,023255814 & 0,008333333 \\
\hline Universidad de Alicante & 1 & 0,023255814 & 0,008333333 \\
\hline Universidad de Burgos & 2 & 0,046511628 & 0,016666667 \\
\hline Universidad de Deusto & 3 & 0,069767442 & 0,025 \\
\hline Universidad de Deusto, San Sebastian & 1 & 0,023255814 & 0,008333333 \\
\hline Universidad de Leon & 1 & 0,023255814 & 0,008333333 \\
\hline Universidad de Oviedo & 1 & 0,023255814 & 0,008333333 \\
\hline Universidad de Salamanca & 1 & 0,023255814 & 0,008333333 \\
\hline Universidad de Santiago de Compostela & 1 & 0,023255814 & 0,008333333 \\
\hline Universidad de Sevilla & 3 & 0,069767442 & 0,025 \\
\hline Universidad de Valladolid & 1 & 0,023255814 & 0,008333333 \\
\hline Universidad Pablo de Olavide & 4 & 0,093023256 & 0,033333333 \\
\hline Universidad Pontificia Comillas & 1 & 0,023255814 & 0,008333333 \\
\hline Universidad da Coruńa & 1 & 0,023255814 & 0,008333333 \\
\hline
\end{tabular}




\begin{tabular}{|c|c|c|c|}
\hline Universitat de Barcelona & 6 & 0,139534884 & 0,05 \\
\hline Universitat de Girona & 1 & 0,023255814 & 0,008333333 \\
\hline Universitat de València & 4 & 0,093023256 & 0,033333333 \\
\hline Universitat Pompeu Fabra & 1 & 0,023255814 & 0,008333333 \\
\hline Estados Unidos & 10 & & \\
\hline Columbia University & 1 & 0,1 & 0,008333333 \\
\hline Southern Methodist University & 1 & 0,1 & 0,008333333 \\
\hline The New School & 2 & 0,2 & 0,016666667 \\
\hline University of California, Berkeley & 3 & 0,3 & 0,025 \\
\hline University of Oregon & 1 & 0,1 & 0,008333333 \\
\hline University of Virginia & 1 & 0,1 & 0,008333333 \\
\hline Yale University & 1 & 0,1 & 0,008333333 \\
\hline França & 17 & & \\
\hline Aix Marseille Université & 1 & 0,058823529 & 0,008333333 \\
\hline $\begin{array}{l}\text { École des Hautes Études en Sciences } \\
\text { Sociales }\end{array}$ & 1 & 0,058823529 & 0,008333333 \\
\hline Université de Limoges & 1 & 0,058823529 & 0,008333333 \\
\hline Université de Nîmes & 1 & 0,058823529 & 0,008333333 \\
\hline Université de Strasbourg & 1 & 0,058823529 & 0,008333333 \\
\hline Université Panthéon Sorbonne - Paris I & 5 & 0,294117647 & 0,041666667 \\
\hline Université Panthéon-Assas - Paris II & 2 & 0,117647059 & 0,016666667 \\
\hline $\begin{array}{l}\text { Université Paris Ouest Nanterre La } \\
\text { Défense - Paris X }\end{array}$ & 3 & 0,176470588 & 0,025 \\
\hline Université Paris-Sud - Paris XI & 1 & 0,058823529 & 0,008333333 \\
\hline Université Sorbonne Nouvelle - Paris III & 1 & 0,058823529 & 0,008333333 \\
\hline Itália & 13 & & \\
\hline Istituto Universitario Europeo & 1 & 0,076923077 & 0,008333333 \\
\hline $\begin{array}{l}\text { Pontificia Università San Tommaso D'Aquin } \\
\text { o }\end{array}$ & 1 & 0,076923077 & 0,008333333 \\
\hline Università Commerciale Luigi Bocconi & 1 & 0,076923077 & 0,008333333 \\
\hline Università Degli Studi Del Molise & 1 & 0,076923077 & 0,008333333 \\
\hline Università Degli Studi Di Firenze & 1 & 0,076923077 & 0,008333333 \\
\hline Università Degli Studi Di Milano, Milano & 1 & 0,076923077 & 0,008333333 \\
\hline $\begin{array}{l}\text { Università Degli Studi Di Napoli } \\
\text { Federico II }\end{array}$ & 1 & 0,076923077 & 0,008333333 \\
\hline Università Degli Studi Di Padova & 1 & 0,076923077 & 0,008333333 \\
\hline Università Degli Studi Di Perugia & 1 & 0,076923077 & 0,008333333 \\
\hline $\begin{array}{l}\text { Università Degli Studi Di Roma "Tor Verg } \\
\text { ata" }\end{array}$ & 1 & 0,076923077 & 0,008333333 \\
\hline Università Del Salento & 2 & 0,153846154 & 0,016666667 \\
\hline
\end{tabular}




\begin{tabular}{l|r|r|r}
\hline Università Di Bologna & 1 & 0,076923077 & 0,008333333 \\
\hline Paraguai & 1 & & \\
\hline Universidad Nacional de Asunción & 1 & 1 & 0,008333333 \\
\hline Portugal & 16 & & \\
\hline Universidade Católica Portuguesa & 1 & 0,0625 & 0,008333333 \\
\hline Universidade de Coimbra & $\rightarrow 9$ & 0,5625 & 0,075 \\
\hline Universidade de Évora & 1 & 0,0625 & 0,008333333 \\
\hline Universidade de Lisboa & 4 & 0,25 & 0,033333333 \\
\hline Universidade do Minho & 1 & 0,0625 & 0,008333333 \\
\hline República Checa & 1 & & \\
\hline Univerzita Karlova V Praze & 1 & & 0,008333333 \\
\hline Total: 73 instituiçóes & 120 & & \\
\hline
\end{tabular}

Fontes: Plataforma Sucupira, Avaliação Quadrienal CAPES (2017a; 2017b).

Calculadas as frequências, verificamos a proeminência da Universidade de Coimbra, seguida pelas universidades Complutense de Madrid, Barcelona e Paris I. A única instituição estadunidense na lista dos centros com maior peso é Berkeley, superando Harvard - destacada na série anterior. Surpreendentemente, Harvard Law School sequer aparece na listagem, embora haja significativo peso simbólico para seus programas de formaçáo jurídica. Caso a nossa análise também apreendesse estágios de curta duração, mais voltados para a prática profissional em certas especialidades, como o Direito Econômico, Empresarial ou Financeiro (ENGELMANN, 2012, p. 489), possivelmente essa instituição e outros espaços norte-americanos constariam do rol.

\section{Série temporal 2007-2017}

Entre 2007 e 2017, com relação à série anterior, menos docentes doutoraramse no estrangeiro $(-14,17 \%)$. Embora fosse um momento de incentivo aos estudos no exterior por políticas federais, principalmente até o segundo Governo Lula, o período também compreendeu a desaceleração do fomento à pesquisa, muito em decorrência das crises política e econômica deflagradas em gabinetes posteriores. Ainda assim, as taxas de titulados depois de 1996 são expressivas (223 casos em 21 anos), quando comparadas com o período 1965-1995 (75 casos em 30 anos). 
Tabela 10 - Países de formação: série temporal 2007-2017

\begin{tabular}{l|l}
\hline Países & \#Casos $\left(\mathbf{w}_{\mathbf{i}}\right)$ \\
\hline Espanha & 24 \\
\hline França & 21 \\
\hline Itália & 18 \\
\hline Portugal & 14 \\
\hline Alemanha & 13 \\
\hline Estados Unidos & 8 \\
\hline Reino Unido & 2 \\
\hline Colômbia & 1 \\
\hline Suíça & 1 \\
\hline Uruguai & 1 \\
\hline Total & 103 \\
\hline
\end{tabular}

Fontes: Plataforma Sucupira, Avaliação Quadrienal CAPES (2017a; 2017b).

Observamos três ocorrências principais: França, Itália e Alemanha mantiveram-se como espaços procurados, reafirmando a tendência histórica verificada desde a primeira geração; os Estados Unidos continuam sendo opção procurada para doutoramento no exterior; e houve retomada do interesse por Portugal, além da manutenção da Espanha como o país que mais ofertou profissionais ao sistema de pós-graduação brasileiro. As instituições espanholas lideram em número de casos, mas a Universidade de Coimbra consta como um centro de circulação importante desde a última década, servindo como verdadeiro núcleo, ainda que pese a pulverização de espaços de formação ter sido mantida em todas as séries temporais examinadas. 
Gráfico 4 - Porcentagem de países de formação: série temporal 2007-2017

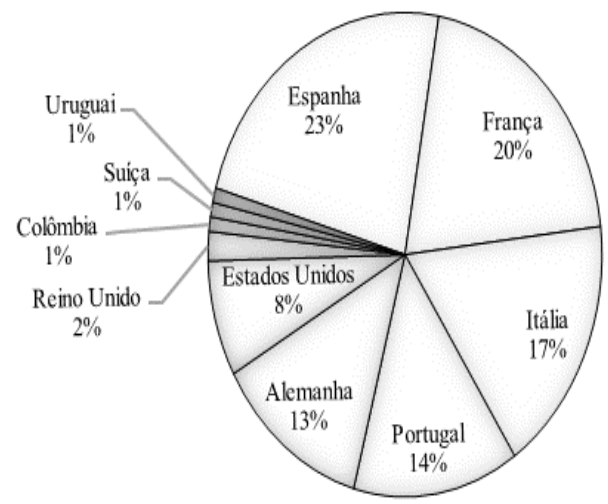

Fontes: Plataforma Sucupira, Avaliação Quadrienal CAPES (2017a; 2017b).

A procura pela Península Ibérica coincide com o período de estreitamento de laços entre associações de pesquisadores brasileiros e europeus. É revelador o volume de encontros organizados pelo Conselho Nacional de Pesquisa e Pós-Graduação em Direito, a principal associação da área no Brasil, naquela região. Somente nos últimos quatro anos, foram realizadas atividades acadêmicas em Barcelona - 2014, em Madri - 2015, em Oñati - 2016, em Braga - 2017 e, mais recentemente, em Zaragoza 2018 (CONPEDI, 2018). Como esses eventos internacionais aparentam ter tido início na última década, a expectativa é que análises vindouras continuem observando a colaboração estreita entre universidades ibéricas e brasileiras, lado-a-lado com instituiçôes historicamente presentes no rol de formadores, como as universidades de Paris I, München e Tor Vergata.

Ponderados os resultados por instituição e país, as universidades francesas, italianas, alemãs e, sobretudo, espanholas apresentam grande volume de titulados seguindo a tendência apontada nas séries temporais anteriores. Destacamos, todavia, a situação de Portugal. Algumas universidades que despontam desde a série anterior, como Lisboa e, principalmente, Coimbra, seguem como espaços de formação significativos, considerando o volume de egressos que tem como destino a docência na pós-graduação brasileira. 
Tabela 11 - Instituiçốes formadoras, egressos e valor ponderado: série temporal 2007-2017

\begin{tabular}{|c|c|c|c|}
\hline País/Instituição & Egressos $\left(\mathrm{x}_{\mathrm{i}}\right)$ & $\left(w_{p}\right)$ & $\left(\mathrm{x}_{\mathrm{w}}\right)$ \\
\hline Alemanha & 13 & & \\
\hline Albert-Ludwigs-Universität Freiburg & 1 & 0,07692308 & 0,00970874 \\
\hline Georg-August-Universität Göttingen & 1 & 0,07692308 & 0,00970874 \\
\hline Goethe-Universität Frankfurt am Main & 2 & 0,15384615 & 0,01941748 \\
\hline Humboldt-Universität Zu Berlin & 1 & 0,07692308 & 0,00970874 \\
\hline Johannes Gutenberg-Universität Mainz & 1 & 0,07692308 & 0,00970874 \\
\hline $\begin{array}{l}\text { Ludwig-Maximilians- } \\
\text { Universität München }\end{array}$ & 3 & 0,23076923 & 0,02912621 \\
\hline Ruprecht-Karls-Universität Heidelberg & 1 & 0,07692308 & 0,00970874 \\
\hline Universität Bremen & 1 & 0,07692308 & 0,00970874 \\
\hline Universität Osnabrück & 1 & 0,07692308 & 0,00970874 \\
\hline Universität Zu Köln & 1 & 0,07692308 & 0,00970874 \\
\hline Colômbia & 1 & & \\
\hline Universidad Nacional de Colombia & 1 & 1 & 0,00970874 \\
\hline Espanha & 24 & & \\
\hline $\begin{array}{l}\text { Asociación Universitaria Iberoamericana } \\
\text { de Postgrado }\end{array}$ & 1 & 0,04166667 & 0,00970874 \\
\hline Universidad Autónoma de Madrid & 2 & 0,08333333 & 0,01941748 \\
\hline Universidad Complutense de Madrid & 3 & 0,125 & 0,02912621 \\
\hline Universidad de Alicante & 3 & 0,125 & 0,02912621 \\
\hline $\begin{array}{l}\text { Universidad de Castilla-La Mancha, } \\
\text { Toledo }\end{array}$ & 1 & 0,04166667 & 0,00970874 \\
\hline Universidad de Granada & 1 & 0,04166667 & 0,00970874 \\
\hline Universidad de Salamanca & 3 & 0,125 & 0,02912621 \\
\hline Universidad de Sevilla & 2 & 0,08333333 & 0,01941748 \\
\hline Universidad de Valladolid & 1 & 0,04166667 & 0,00970874 \\
\hline Universidad de Zaragoza & 2 & 0,08333333 & 0,01941748 \\
\hline Universidad Pablo de Olavide & 4 & 0,16666667 & 0,03883495 \\
\hline Universitat Pompeu Fabra & 1 & 0,04166667 & 0,00970874 \\
\hline Estados Unidos & 8 & & \\
\hline George Washington University & 1 & 0,125 & 0,00970874 \\
\hline Harvard University & 1 & 0,125 & 0,00970874 \\
\hline Indiana University & 1 & 0,125 & 0,00970874 \\
\hline New York University & 1 & 0,125 & 0,00970874 \\
\hline Pace University & 1 & 0,125 & 0,00970874 \\
\hline University of California, Berkeley & 1 & 0,125 & 0,00970874 \\
\hline University of Pennsylvania & 1 & 0,125 & 0,00970874 \\
\hline University of Texas, Austin & 1 & 0,125 & 0,00970874 \\
\hline França & 21 & & \\
\hline
\end{tabular}




\begin{tabular}{|c|c|c|c|}
\hline Aix Marseille Université & 2 & 0,0952381 & 0,01941748 \\
\hline $\begin{array}{l}\text { École des Hautes Études en Sciences S } \\
\text { ociales }\end{array}$ & 1 & 0,04761905 & 0,00970874 \\
\hline École Pratique des Hautes Études & 1 & 0,04761905 & 0,00970874 \\
\hline Institut d'Études Politiques de Paris & 1 & 0,04761905 & 0,00970874 \\
\hline Université de Limoges & 2 & 0,0952381 & 0,01941748 \\
\hline Université d'Orléans & 1 & 0,04761905 & 0,00970874 \\
\hline Université Montpellier I & 1 & 0,04761905 & 0,00970874 \\
\hline Université Panthéon Sorbonne - Paris I & $\rightarrow 6$ & 0,28571429 & 0,05825243 \\
\hline Université Panthéon-Assas - Paris II & 1 & 0,04761905 & 0,00970874 \\
\hline Université Paris Descartes - Paris V & 1 & 0,04761905 & 0,00970874 \\
\hline Université Paris-Sorbonne - Paris IV & 2 & 0,0952381 & 0,01941748 \\
\hline $\begin{array}{l}\text { Université Sorbonne Nouvelle - } \\
\text { Paris III }\end{array}$ & 1 & 0,04761905 & 0,00970874 \\
\hline Université Toulouse I - Capitole & 1 & 0,04761905 & 0,00970874 \\
\hline Itália & 18 & & \\
\hline Pontificia Università Urbaniana & 1 & 0,05555556 & 0,00970874 \\
\hline Pontificio Ateneo Sant'Anselmo & 1 & 0,05555556 & 0,00970874 \\
\hline $\begin{array}{l}\text { Università Degli Studi "Magna Graecia" } \\
\text { Di Catanzaro }\end{array}$ & 1 & 0,05555556 & 0,00970874 \\
\hline $\begin{array}{l}\text { Università Degli Studi Di Bari Aldo M } \\
\text { oro }\end{array}$ & 1 & 0,05555556 & 0,00970874 \\
\hline Università Degli Studi Di Firenze & 2 & 0,11111111 & 0,01941748 \\
\hline Università Degli Studi Di Perugia & 1 & 0,05555556 & 0,00970874 \\
\hline $\begin{array}{l}\text { Università Degli Studi Di Roma "La S } \\
\text { apienza" }\end{array}$ & 2 & 0,11111111 & 0,01941748 \\
\hline $\begin{array}{l}\text { Università Degli Studi Di Roma "Tor } \\
\text { Vergata" }\end{array}$ & 3 & 0,16666667 & 0,02912621 \\
\hline Università Degli Studi Di Urbino & 1 & 0,05555556 & 0,00970874 \\
\hline Università Degli Studi Roma Tre & 3 & 0,16666667 & 0,02912621 \\
\hline Università Di Macerata & 2 & 0,11111111 & 0,01941748 \\
\hline Portugal & 14 & & \\
\hline Universidade de Coimbra & $\rightarrow 10$ & 0,71428571 & 0,09708738 \\
\hline Universidade Católica Portuguesa & 2 & 0,14285714 & 0,01941748 \\
\hline Universidade de Lisboa & 2 & 0,14285714 & 0,01941748 \\
\hline Reino Unido & 2 & & \\
\hline University of London & 1 & 0,5 & 0,00970874 \\
\hline $\begin{array}{l}\text { University of London - } \\
\text { The London School of... }\end{array}$ & 1 & 0,5 & 0,00970874 \\
\hline Suíça & 1 & & \\
\hline Université de Genève & 1 & 1 & 0,00970874 \\
\hline
\end{tabular}


Vinicius Wohnrath

\begin{tabular}{l|r|r|r}
\hline Uruguai & 1 & & \\
\hline Universidad de La República & 1 & 1 & 0,00970874 \\
\hline Total: 62 instituiçóes & 103 & & \\
\hline
\end{tabular}

Fontes: Plataforma Sucupira, Avaliação Quadrienal CAPES (2017a; 2017b).

Acreditamos que a tendência de formação na Europa - prevista por Engelmann (2008) para Espanha e França - deverá ser consolidada nas próximas gerações de professores com estudos doutorais no exterior. Todavia, conforme apreendemos do movimento das últimas duas séries temporais, a França poderá, aos poucos, ceder lugar a Portugal - mas, sem deixar o rol dos principais centros buscados pelos professores de Direito. Ademais, esse crescente interesse pelas instituições espanholas e portuguesas pode estar diretamente relacionado com os investimentos recentes de associações de juristas brasileiros, visando estreitar laços com pesquisadores ibéricos.

\section{Conclusão}

Neste artigo, foram inspecionados os locais de formação e os momentos de doutoramento no estrangeiro dos docentes atualmente cadastrados nos programas de pós-graduação em Direito autorizados pela CAPES. Revisitamos a pesquisa de Engelmann (2008), além de ampliar seus dados para os últimos dez anos, considerando as características dos grupos examinados.

Todavia, nossa estratégia de pesquisa diferiu da aplicada no estudo revisitado. Utilizando a Plataforma Lattes, a investigação anterior coletou informaçôes sobre todos os níveis de formação, enfrentando uma série de dificuldades, como a inexatidão de informações voluntariamente prestadas e a ausência de currículos cadastrados (ENGELMANN, 2008, p. 149). Por sua vez, recuperamos os Documentos de Área e outras bases de dados da Avaliação Quadrienal (CAPES, 2017a; 2017b) disponibilizadas pela Plataforma Sucupira, visando uma população mais restrita: apenas os doutores inscritos em programas de pós-graduação. Na década passada, esse recurso não tinha o mesmo alcance. Para facilitar a visualização dos dados e o tratamento das bases, aplicamos estatística descritiva.

Ao selecionarmos somente os docentes com formação doutoral no exterior, constatamos uma baixa diversificação de países formadores ao longo da série histórica (1965-1980, 9 países; 1981-1995, 13 países; 1995-2005, 11 países; 2006-2017, 10 países), concentrada no eixo entre Europa Ocidental e Estados Unidos. Quando confrontadas as situaçóes atual e anterior do espaço, percebemos que esses lugares 
dominantes vêm apresentando certa uniformidade, com raras aberturas para outros centros e redes de colaboração acadêmica. Também identificamos que, inicialmente, havia maior procura pela França, Itália e Alemanha, enquanto que nas últimas séries vem ocorrendo um deslocamento progressivo em direção à Espanha e Portugal. Essa é uma variação no padrão de formação internacional.

Já a tendência para constituição de polos de formação de juristas na França e na Espanha prevista por Engelmann (2008), ao que parece, vem em parte se confirmando - principalmente para o caso espanhol, seguido pela retomada da procura pelas instituiçốes portuguesas. Nesse sentido, observamos com atenção possíveis redes internacionais formadas entre associações de juristas brasileiros e ibéricos. A realização reiterada de encontros científicos do CONPEDI na Espanha e em Portugal não passa desapercebida. Acreditamos que esse direcionamento pode intensificar o intercâmbio de estudantes e pesquisadores através do Atlântico.

Quanto às universidades formadoras, semelhante aos resultados da pesquisa revisitada, persiste o fenômeno da pulverização, dificultando o estabelecimento de núcleos de colaboração internacional duradouros (1965-1980, 16 instituições; 19811995, 39 instituições; 1995-2005, 73 instituições; 2006-2017, 62 instituições). Merece destaque a procura pela Universidade de Coimbra na última década. Apresentando maior volume de titulados, tem se tornado caminho preferencial para parte dos professores que buscam Portugal como lugar de doutoramento - seja pela familiaridade com o idioma, com a cultura lusitana ou com o sistema jurídico romano-germânico. Por outro lado, em comparação com as séries anteriores, nesse mesmo período os EUA foram menos procurados. Um desafio é entender as circunstâncias das eleiçôes desses lugares de passagem e como vem sendo operadas as reelaboraçôes dos saberes, na área do Direito, no atual processo de circulação internacional.

Este artigo, quando lido junto ao trabalho publicado anteriormente por Engelmann (2008), fornece elementos que contribuem para uma melhor visualização das mudanças e manutenções nos espaços de circulação dos professores de Direito atuantes no Brasil em diferentes momentos, sobretudo no contexto da expansão da pós-graduação na área, iniciada nos anos 1990, e das políticas de internacionalização da pesquisa jurídica (ARAÚJO, 2000; ENGELMANN, 2006; FRAGALE FILHO e VERONESE, 2004). Ademais, permite que outros pesquisadores também explorem os dados coletados e comparados, elaborando novas explicações sobre como esse espaço social vem se constituindo historicamente. Por fim, outro esforço que deve ser 
84 | Vinicius Wohnrath

realizado - e que consta como próxima etapa em nossa agenda de pesquisa - é compreender em quais condiçóes ocorre a recepção dos juristas formados no exterior pelos programas de pós-graduação brasileiros.

Vinicius Wohnrath é Doutor em Educação pela Universidade Estadual de Campinas. Pós-doutorando no Focus/Unicamp, na linha Educação e Ciências Sociais, com bolsa Fapesp (17/182510). E-mail: vinicius.wohnrath@gmail.com.

\section{Referências}

ALMEIDA, Ana Maria Fonseca de; CANÊDO, Letícia Bicalho; GARCIA JR., Afrânio Raul; GRÜN, Roberto. Apresentação. In: ALMEIDA, Ana Maria Fonseca de; BITTENCOURT, Agueda; CANÊDO, Letícia Bicalho; GARCIA JR., Afrânio Raul (Orgs). Circulação internacional e formação intelectual das elites brasileiras. Campinas: Editora da Unicamp, 2004.

ALMEIDA, Rodolfo; ZANLORENSSI, Gabriel. A distribuição de pessoas com doutorado pelo Brasil. Jornal Nexo, 4 maio 2017.2 Disponível em: <https:/www.nexojornal.com.br/grafico/2017/10/23/A-distribui\%C3\%A7\%C3\%A3o-de-pessoascom-doutorado-pelo-Brasil>. Acesso em: 7 nov. 2018.

ARAÚJO, Nádia de. Formação do jurista pesquisador: pressupostos e requisitos, técnicas de pesquisa e ensino na pós-graduação. Direito, Estado e Sociedade, n. 14, p. 23-38, 2000.

CANÊDO, Letícia Bicalho. Conhecimentos de Estado e elites internacionais: a Fundação Ford no Brasil e seus beneficiários. $41^{\circ}$ Encontro Anual ANPOCS. Caxambu: Associação Nacional de PósGraduação e Pesquisa em Ciências Sociais, 2017. Disponível em: $<$ https://www.anpocs.com/index.php/papers-40-encontro-2/gt-30/gt10-24/10685-conhecimentosde-estado-e-elites-internacionais-a-fundacao-ford-no-brasil-e-seus-beneficiarios/file>. Acesso em: 7 nov. 2018.

CARVALHO, José Murilo de. A formação das almas: o imaginário da República no Brasil. São Paulo: Companhia das Letras, 1998.

. A construção da ordem: a elite política imperial [seguido de] Teatro de sombras: a política imperial. 7. ed. Rio de Janeiro: Civilização Brasileira, 2012.

CONSELHO Nacional Pesquisa e Pós-Graduação em Direito (CONPEDI). Eventos CONPEDI: eventos passados. 2018. Disponível em: <https://www.conpedi.org.br/eventos/>. Acesso em: 6 nov. 2018.

CAPES. Coordenação de Aperfeiçoamento de Pessoal de Nível Superior. Plataforma Sucupira. 2017a. Disponível em: <https://sucupira.capes.gov.br/sucupira/>. Acesso em: 10 fev. 2018. 
. Database CAPES - Avaliação Quadrienal 2017. Área do Direito. 2017b. Disponível em: <http://avaliacaoquadrienal.capes.gov.br/>. Acesso em: 10 fev. 2018.

CURY, Carlos Roberto Jamil. Qualificação pós-graduada no exterior. In: ALMEIDA, Ana Maria Fonseca de; BITTENCOURT, Agueda; CANÊDO, Letícia Bicalho; GARCIA JR., Afrânio Raul (Orgs). Circulação internacional e formação intelectual das elites brasileiras. Campinas: Editora da Unicamp, 2004.

Estado e políticas de financiamento em educação. Educação \& Sociedade, v. 28, n. 100, p. 831-855, 2007.

DEZALAY, Yves; GARTH, Bryant. Juristes purs et marchands de droit. Division du travail de domination symbolique et aggiornamento dans le champ du droit. Revue des sciences sociales du politique, v. 3, n. 10, p. 70-91, 1990.

La Mondialisation des Guerres de Palais: La restructuration du pouvoir d'État en Amérique Latine, entre notables du droit et "Chicago Boys". Paris: Seuil, 2002.

ENGELMANN, Fabiano. La redéfinition de l'enseignement et de l'espace juridique brésilien. Cahiers du Brésil Contemporain, n. 54-55, p. 177-201, 2004.

Fabris, 2006.

. Sociologia do campo jurídico: juristas e usos do direito. Porto Alegre: Sérgio Antônio

Diversification de l'espace juridique et invention de la «critique du droit » au Brésil dans les années 1990. Droit et societé, n. 1, p. 153-169, 2007.

- Estudos no exterior e mediaçáo de modelos institucionais: o caso dos juristas brasileiros. Revista de Sociologia Política, v. 16, p. 145-157, 2008.

Globalização e poder de Estado: circulação internacional de elites e hierarquias do campo jurídico brasileiro. DADOS Revista de Ciências Sociais, v. 55, n. 2, p. 487-516, 2012.

. Da "crítica do Direito" ao "combate à corrupção": deslocamentos do ativismo políticojudicial. Contemporânea, v. 7, n. 2, p. 297-312, 2017.

FUNDAÇÃO GETÚlIO VARGAS - FGV. História Oral do Campo Jurídico em São Paulo: projeto de constituição de um acervo de entrevistas com personagens do direito paulista. Entrevista com José Eduardo Faria. 2011. Disponível em: <http://cpdoc.fgv.br/campojuridico/jose-eduardo-faria>. Acesso em: 31 jan. 2018.

. Observatório do Ensino do Direito. 2013. Disponível em: <http://direitosp.fgv.br/observatorio-ensino-Direito>. Acesso em: 06 nov. 2018.

FRAGALE FILHO, Roberto; VERONESE, Alexandre. A pesquisa em Direito: diagnóstico e perspectivas. Revista Brasileira de Pós-Graduação, v. 1, n. 2, p. 53-70, 2004.

GALVÃO, Antônio Carlos Filgueira; ARANHA, Sofia Cristina Daher; CARRIJO, Tomáz Back; SANTOS, Dayany de Oliveira; Oliveira JR., Carlos Duarte de. Mestres e doutores 2015 - Estudos da demografia da base técnico científica brasileira. Brasília: Centro de Gestão e Estudos Estratégicos (CGEE), 2016.

GHIRALDI, José Garcez; CUNHA, Luciana Gross; FEFERBAUM, Marina; PRETZEL, Bruna Romano; NINOMIYA, Fernando Issao; KLAFKE, Guilherme Forma; CHAVENCO, Maurício. Detalhamento regional da área de Direito: ensino superior 2012 - docentes. São Paulo: Fundação Getúlio Vargas, 2013.

LOPES, José Reinaldo de Lima. O direito na história: lições introdutórias. São Paulo: Atlas, 2000. 
86 | Vinicius Wohnrath

LYRA FILHO, Roberto. O que é direito. São Paulo: Brasiliense, 1987.

MARTINS, Carlos Benedito; CARVALHO, Inaia Maria Moreira de. Mestres e doutores em Direito. In: VELLOSO, Jacques (Orgs.). A pós-graduação no Brasil: formação e trabalho de mestres e doutores no País. Brasília: CAPES, 2003.

QUEIROZ, Rafael Maffei Rabelo; ACCA, Thiago; GAMA, Bruno. De los bancos universitarios a la toga: la trayectoria académica de los ministros del Supremo Tribunal Federal brasileño (19882013). Precedente, v. 8, p. 67-104, 2017.

SOUSA JUNIOR, José Geraldo de. O Direito Achado na Rua: concepção e prática. v. 2 Rio de Janeiro: Lumen Juris, 2015.

VENÂNCIO FILHO, Alberto. Das arcadas ao bacharelismo: 150 anos de ensino jurídico no Brasil. 2. ed. São Paulo: Perspectiva, 2011.

WOLKMER, Antônio Carlos. Introdução ao pensamento jurídico crítico. São Paulo: Acadêmica, 1995.

Texto recebido em 15 de agosto de 2018. Aprovado em 31 de outubro de 2018. 